\title{
Parental Oral Health Literacy and Child Oral Health Impact Profile among 15-year-old Schoolchildren in Davangere City, Karnataka, India
}

\author{
${ }^{1}$ Adapa Sumabindu, ${ }^{2} \mathrm{~V}$ Hirekalmath Sushanth, ${ }^{3} \mathrm{PG}$ Naveen Kumar, ${ }^{4} \mathrm{GM}$ Prashant, ${ }^{5}$ Mohamed Imranulla
}

\begin{abstract}
Introduction: The public can encounter an overwhelming amount of complex health information in everyday life. The growth in information and the rapid advances in dental scientific knowledge require that the public should have an understanding of oral health to make good decisions about their own and their children's oral health. Studies have reported that parental education has a direct impact on oral health of children.
\end{abstract}

Aim: To determine parental oral health literacy $(\mathrm{OHL})$ and children oral health impact profile among 15-year-old schoolchildren in Davangere city, Karnataka, India.

\begin{abstract}
Materials and methods: A cross-sectional study was conducted using health literacy in dentistry (HeLD) dental scale to assess the $\mathrm{OHL}$ of parents, and their children's oral health-related quality-of-life (OHRQoL) was assessed using child oral health impact profile (COHIP) among 15-year-old schoolchildren. Questionnaire was distributed to the children and their parents for collecting the data. This was followed by a clinical oral examination of children to record the number of decayed, missing, and filled components of their permanent dentition. Chi-squared test and linear logistic regression were used to analyze the data using Statistical Package for the Social Sciences (SPSS) version 20.
\end{abstract}

Results: The present study showed that $57.5 \%$ of parents have educational qualification below intermediate level and $36 \%$ were not able to pay to consult a dentist. However, only $17.1 \%$ of students in the present study agreed that they had pain in their teeth and $73 \%$ of students expressed that they were confident of their teeth. The mean number of decayed, missing, or filled teeth (DMFT) of the students in the study was $1.43 \pm 1.64$.

Conclusion: The relation of parental OHL and child OHRQoL is not a direct cause-and-effect connection, but rather a more elusive relationship. These results suggest that education and counseling of parents with low OHL levels may be an important component for the oral care of their children.

Keywords: Child oral health impact profile, Health literacy in dentistry, Schoolchildren.

${ }^{1}$ Postgraduate Student (Final Year), ${ }^{2,5}$ Reader, ${ }^{3}$ Professor and Head, ${ }^{4}$ Professor

${ }^{1-5}$ Department of Public Health Dentistry, College of Dental Sciences, Davangere, Karnataka, India

Corresponding Author: Adapa Sumabindu, Postgraduate Student (Final Year), Department of Public Health Dentistry College of Dental Sciences, Davangere, Karnataka, India, Phone: +919591610774, e-mail: adapasumabindu@gmail.com
How to cite this article: Sumabindu $A$, Sushanth $V H$, Kumar PGN, Prashant GM, Imranulla M. Parental Oral Health Literacy and Child Oral Health Impact Profile among 15-yearold Schoolchildren in Davangere City, Karnataka, India. J Oral Health Comm Dent 2017;11(3):61-67.

\section{Source of support: Nil}

Conflict of interest: None

\section{INTRODUCTION}

The preservation of healthy teeth is one of the key health issues in childhood. Family creates an environment necessary for healthy lifestyle, increases self-confidence, and helps habit formation in children. Adoption of consistent behavioral habits in childhood takes place at home, with the parents being the primary model for behavior. Parental knowledge and attitudes toward the importance of oral hygiene play a major role. Low-education families do not pay enough attention to dental care measures. ${ }^{1,2}$

Poor general literacy and, in particular, poor health literacy skills are recognized as possible causes of health disparities. The multilevel consequences of low health literacy have been reviewed and these include negative health behaviors, reduced utilization of preventive health services, and poorer adherence to therapeutic protocols. Limited reading skills are usually associated with a limited understanding of the concepts of risk, chronicity, and their associated treatment protocols. ${ }^{3,4}$

In the recent scenario, many advanced indices are available to measure literacy as it relates to oral health. The HeLD developed recently takes a broad approach to measure an individual's ability to seek, understand, and utilize oral health information to make appropriate oral health-related decisions. ${ }^{5-7}$

It has been suggested that quality-of-life measures should include "positive" and "negative" items to encompass all aspects, which may impact upon well-being. Multiple measures of OHRQoL have been developed and standardized for use in adults. Efforts have been made to develop a measure of OHRQoL that would be appropriate for use with children. The COHIP measures oral health, functional well-being, social-emotional wellbeing, school environment, and self-image as well as the overall OHRQoL of the child. It was designed to be used 
with a broad age ( $8-15$ years) across oral conditions and include positive (e.g., confidence, attractiveness) as well as negative aspects of OHRQoL. ${ }^{6,8}$

Both the above-mentioned scales are the latest in their domain and literature search showed hardly any studies designed to assess the child's self-reported OHRQoL using COHIP and their parent's OHL using HeLD. Hence, the aim of the present cross-sectional study was to assess parental OHL using HeLD and child's oral health impact profile using COHIP among 15-year-old schoolchildren in Davangere city, India.

\section{MATERIALS AND METHODS}

A cross-sectional study was conducted among 15 -yearsold schoolchildren (both private and government) and their parents in Davangere city from July to September 2016. Ethical approval was obtained from the Institutional Ethical Board and informed consent was obtained from the parents and a verbal assent was obtained from the schoolchildren.

\section{Sample Size Estimation}

A pilot study was conducted among 30 students and their parents attending the nearby school to assess the feasibility of the study and for sample size estimation.

Sample size was estimated by using the following formula

$$
\begin{gathered}
\text { Sample size }=n=\frac{z^{2} \times p \times q}{d^{2}} \\
\text { where } \\
d=\text { allowable error }=15 \% \text { of } p \\
p=\text { prevalence of dental caries }=30 \\
q=100-p=70 \\
z=1.96
\end{gathered}
$$

Substituting the values obtained from the pilot study in the following formula,

$$
\text { Sample size }=\frac{(1.96)^{2} \times 30 \times 70}{3^{2}}
$$

Hence, the sample size was approximately 398. But, considering the dropouts and missing data, sample was rounded off to 414 . Pilot study participants were not included in the main study.

The questionnaire used for parents to assess their $\mathrm{OHL}^{8,9}$ and for children to assess their $\mathrm{OHRQOL}^{7}$ was previously validated by piloting, and the appropriate changes have been made before it was finalized for the study. The list of schools obtained from the District Education Office showed that the city is divided into north and south zones. By using the lottery method, two schools from the north and two schools from the south zone were randomly selected for the study. The 15-year-old schoolchildren present on the day of examination and those who gave informed consent were included in the study until the total sample size of 414 was achieved.

Children suffering from severe systemic diseases, not staying with their parents, undergoing orthodontic treatment, and who have undergone dental treatment in the past 3 months were not included in the study.

The study was conducted by a single trained examiner along with an assistant scribe. A structured pro forma was used. The data were collected in three parts. The first part consisted of sociodemographic details of the student and their parents. The second part consisted of COHIP-15 that was rated on a 3-point Likert scale followed by American Dental Association type III clinical oral examination of children within the school premises under strict aseptic precautions to record the number of decayed, missing, and filled components of their permanent dentition. Kappa value for intraexaminer reliability was 0.82 . The third part consisted of HeLD-10 consisting of 10 questionnaires for their parents rated on a 3-point Likert scale. Participants were asked to fill the first and second parts of the pro forma in front of the examiner. Adequate time was provided and later the third part was distributed among the students to carry home and get it back filled by one of their parents with the higher educational qualification. A small incentive like oral hygiene kit was also offered to the students for this purpose.

The data so obtained were entered into the Excel sheet, and descriptive and inferential statistical analyses were made using SPSS version 20.0. The chi-squared test was used to test the association between the responses among the parent and children toward their respective questionnaire. Logistic regression was used to estimate the relationships among educational qualification of parents and their OHL, gender of children, and their OHRQoL. The difference in the means of DMFT was tested using unpaired t-test between male and female children. For all the tests, the level of significance was set up at $\mathrm{p} \leq 0.05$.

\section{RESULTS}

Total sample size comprised 414 students and their parents, with a response rate of $100 \%$. Most of the participating children and their parents were males (Graph 1) and more than half (57.5\%) of the participating parents had attained education below intermediate level (Graph 2).

Table 1 describes the chi-squared results for the significant responses with respect to gender among 15 -year-old schoolchildren about their OHRQoL using COHIP. 


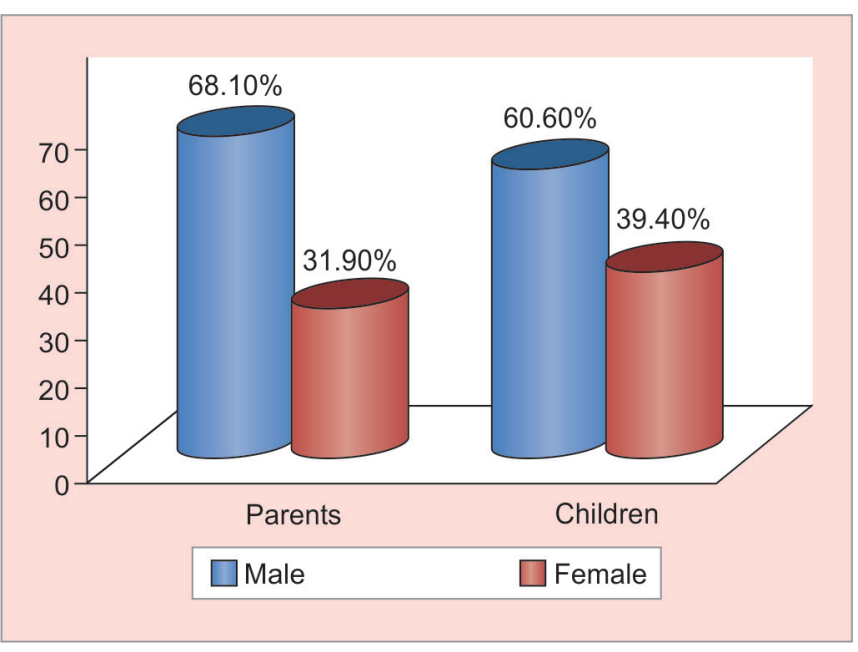

Graph 1: Genderwise distribution of parents and students

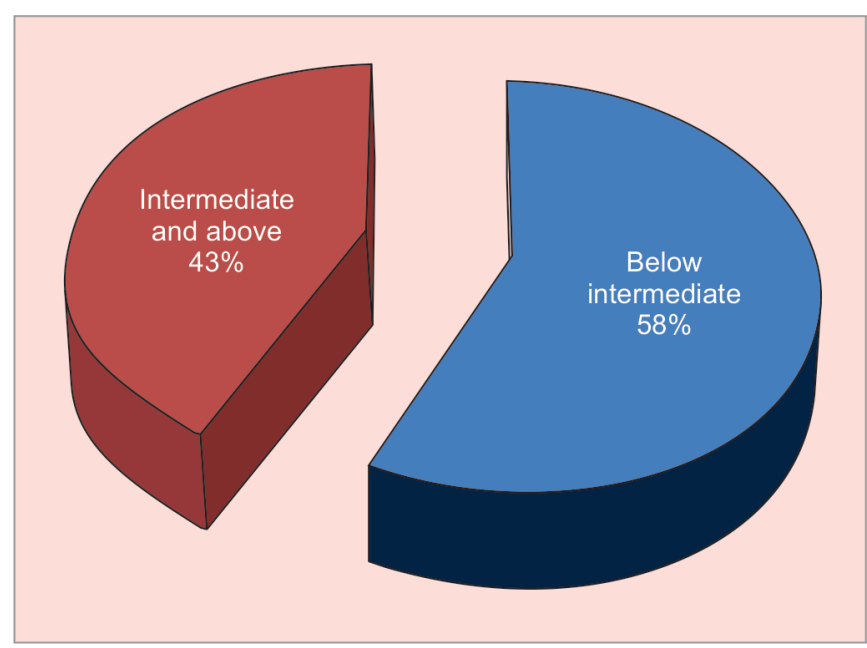

Graph 2: Percentage distribution of parents based on their education

Table 1: Response of 15-year-old schoolchildren about their OHRQoL using COHIP based on their gender

\begin{tabular}{|c|c|c|c|c|}
\hline Questions & Options & Number & Percentage & $p$-value \\
\hline \multirow[t]{3}{*}{ Had pain in your teeth/toothache } & 1 = Disagree & 290 & $70.1 \%$ & $0.048^{*}$ \\
\hline & $2=$ Do not agree & 53 & $12.8 \%$ & \\
\hline & $3=$ Agree & 71 & $17.1 \%$ & \\
\hline \multirow[t]{3}{*}{ Had discolored teeth or spots on your teeth } & 1 = Disagree & 237 & $57.3 \%$ & $0.043^{*}$ \\
\hline & $2=$ Do not agree & 42 & $10.1 \%$ & \\
\hline & 3 = Agree & 135 & $32.6 \%$ & \\
\hline \multirow{2}{*}{ Had crooked teeth or spaces between your teeth } & 2 = Do not agree & 41 & $9.9 \%$ & \\
\hline & $3=$ Agree & 146 & $35.2 \%$ & \\
\hline \multirow[t]{3}{*}{ Had bad breath } & 1 = Disagree & 329 & $79.5 \%$ & $0.003^{* *}$ \\
\hline & 2 = Do not agree & 37 & $8.9 \%$ & \\
\hline & 3 = Agree & 48 & $11.6 \%$ & \\
\hline \multirow{2}{*}{$\begin{array}{l}\text { Had difficulty eating foods you like the most because of your teeth/mouth } \\
\text { or face }\end{array}$} & 1 = Disagree & 337 & $81.4 \%$ & $0.031^{*}$ \\
\hline & 3 = Agree & 36 & $8.7 \%$ & \\
\hline \multirow[t]{3}{*}{ Been worried about what other people think about your teeth/mouth or face } & 1 = Disagree & 309 & $74.6 \%$ & $0.008^{* *}$ \\
\hline & 2 = Do not agree & 36 & $8.7 \%$ & \\
\hline & $3=$ Agree & 69 & $16.7 \%$ & \\
\hline \multirow{3}{*}{$\begin{array}{l}\text { Been teased, bullied, or called names by other children because of your } \\
\text { teeth/mouth or face }\end{array}$} & 1 = Disagree & 350 & $84.5 \%$ & $0.034^{*}$ \\
\hline & 2 = Do not agree & 31 & $7.5 \%$ & \\
\hline & 3 = Agree & 33 & $8 \%$ & \\
\hline \multirow[t]{3}{*}{ Been confident because of your teeth/mouth or face } & 1 = Disagree & 104 & $25.1 \%$ & $0^{* *}$ \\
\hline & 2 = Do not agree & 8 & $1.9 \%$ & \\
\hline & $3=$ Agree & 302 & $73 \%$ & \\
\hline \multirow{3}{*}{$\begin{array}{l}\text { Felt that you were attractive (good looking) because of your teeth/mouth or } \\
\text { face }\end{array}$} & 1 = Disagree & 127 & $30.7 \%$ & $0 * *$ \\
\hline & 2 = Do not agree & 18 & $4.3 \%$ & \\
\hline & $3=$ Agree & 169 & $64.9 \%$ & \\
\hline
\end{tabular}

$\chi^{2}=$ Chi-squared test; ${ }^{*} p \leq 0.05$ significant; ${ }^{* *} p \leq 0.01$ highly significant

Only $17.1 \%$ of the participating schoolchildren agreed that they had pain in their teeth. About 32.6\% children agreed that they have discolored teeth. Less than half $(35.2 \%)$ of the participating schoolchildren agreed that they have spaces between their teeth and only $11.6 \%$ of children said that they have bad breath. Majority of schoolchildren $(74.6 \%)$ disagreed that they are worried about what other people think about their teeth and 84.5\% of children disagreed that they are called or been teased or bullied by other children because of their teeth. About $73 \%$ of children in the study agreed that they are confident because of their teeth.

Table 2 describes the chi-squared results for the significant responses with respect to age, gender, and educational qualification of parents on OHL-based questions of HeLD. 
Table 2: Response of parents on OHL questions of HeLD based on their age, gender, and educational qualification

\begin{tabular}{|c|c|c|c|c|}
\hline Questions & Options & Number & Percentage & $p$-value \\
\hline \multirow[t]{3}{*}{ Are you able to pay attention to dental health needs? } & $1=$ Never & 251 & $60.6 \%$ & 0 ** \\
\hline & $2=$ Occasionally & 34 & $8.2 \%$ & (age, gender, education) \\
\hline & $3=$ Often & 129 & $31.2 \%$ & \\
\hline \multirow{4}{*}{$\begin{array}{l}\text { Are you able to make time for things good for dental } \\
\text { health? }\end{array}$} & $1=$ Never & 251 & $60.62 \%$ & $0^{* *}$ \\
\hline & $2=$ Occasionally & 39 & $9.42 \%$ & (age) \\
\hline & 3 = Often & 124 & $29.95 \%$ & 0.001 \\
\hline & & & & (gender, education) \\
\hline \multirow[t]{3}{*}{ Are you able to fill in dental forms? } & 1 = Never & 214 & $51.6 \%$ & $0^{* *}$ \\
\hline & $2=$ Occasionally & 71 & $17.1 \%$ & (age, gender, education) \\
\hline & $3=$ Often & 129 & $31.1 \%$ & \\
\hline \multirow[t]{3}{*}{ Are you able to read dental information brochures? } & $1=$ Never & 233 & $56.28 \%$ & $0^{* *}$ \\
\hline & $2=$ Occasionally & 26 & $6.28 \%$ & (age, education) \\
\hline & $3=$ Often & 155 & $37.43 \%$ & 0.3 (gender) \\
\hline \multirow[t]{4}{*}{ Are you able to take support to a dental appointment? } & $1=$ Never & 215 & $51.9 \%$ & $0^{* *}$ \\
\hline & $2=$ Occasionally & 78 & $18.8 \%$ & (age) \\
\hline & $3=$ Often & 121 & $29.3 \%$ & $0.001^{* *}$ \\
\hline & & & & (gender, education) \\
\hline \multirow[t]{3}{*}{ Are you able to pay to see a dentist? } & $1=$ Never & 149 & $36 \%$ & $0^{* *}$ \\
\hline & $2=$ Occasionally & 34 & $8.2 \%$ & (age, gender, education) \\
\hline & $3=$ Often & 231 & $55.8 \%$ & \\
\hline \multirow[t]{3}{*}{ Are you able to pay for dental medication? } & $1=$ Never & 152 & $35.7 \%$ & $0^{* *}$ \\
\hline & $2=$ Occasionally & 39 & $9.4 \%$ & (age, gender, education) \\
\hline & $3=$ Often & 223 & $53.9 \%$ & \\
\hline \multirow[t]{6}{*}{ Do you know how to get dentist's appointment? } & $1=$ Never & 176 & $42.5 \%$ & $0^{* *}$ \\
\hline & $2=$ Occasionally & 42 & $10.1 \%$ & (age) \\
\hline & $3=$ Often & 196 & $47.4 \%$ & $0.006^{* *}$ \\
\hline & & & & (gender) \\
\hline & & & & $0.002^{* \star}$ \\
\hline & & & & (education) \\
\hline \multirow[t]{4}{*}{ Are you able to look for a second opinion? } & 1 = Never & 155 & $37.4 \%$ & $0^{* *}$ \\
\hline & $2=$ Occasionally & 39 & $9.4 \%$ & (age, education) \\
\hline & $3=$ Often & 220 & $53.2 \%$ & $0.001^{* *}$ \\
\hline & & & & (gender) \\
\hline \multirow[t]{3}{*}{ Are you able to carry out dental instructions? } & $1=$ Never & 231 & $55.8 \%$ & $0^{* *}$ \\
\hline & $2=$ Occasionally & 19 & $4.6 \%$ & (age, gender, education) \\
\hline & $3=$ Often & 164 & $39.6 \%$ & \\
\hline
\end{tabular}

$\chi^{2}=$ Chi-squared test; ${ }^{*} p \leq 0.05$ significant; ${ }^{* *} p \leq 0.01$ highly significant

Majority of parents $(60.6 \%)$ said that they are not able to pay attention to dental health needs; approximately $60 \%$ of the participating parents said that they are not able to make time for things good for dental health and around half of the participating parents said that they are not able to fill in dental forms and not able to read dental information brochures, and not able to take support for making a dental appointment. More than half of parents were often able to pay for dental medication and are often able to look for a second opinion. About $55.8 \%$ of parents were not able to carry out dental instructions.

Table 3 depicts the regression values of responses among the parents with different education qualification.

Parents with educational qualification above intermediate level are 0.642 times more likely to pay attention to dental health needs and 0.334 times more likely to make time for things good for dental health, and 0.152 times more likely to fill in dental forms. Parents with education above intermediate are 0.408 times more likely to carry out dental instructions compared with parents with education below intermediate level.

Table 4 depicts the regression values of responses among the schoolchildren toward their OHRQoL using COHIP.

Male children had 0.084 times more likely dental pain compared with female children, 0.096 times male children had spaces in between the teeth compared with female children.

Table 5 depicts the difference in the means of DMFT tested using unpaired t-test with respect to gender of 
Table 3: Logistic regression analysis of responses among the parents with different education qualification using HeLD as OHL scale

\begin{tabular}{llllll}
\hline & Regression & & & \multicolumn{2}{c}{ 95\% confidence interval } \\
\cline { 4 - 6 } Questions & coefficient & p-value & Odds ratio & Lower & Upper \\
\hline Are you able to pay attention to dental health needs? & 0.161 & $0^{* *}$ & 0.642 & 1.621 & 2.229 \\
Are you able to make time for things good for dental health? & 0.111 & $0^{* *}$ & 0.334 & 0.691 & 1.211 \\
Are you able to fill in dental forms? & 0.023 & $0.002^{* *}$ & 0.152 & 0.173 & 0.760 \\
Are you able to take support to make a dental appointment? & 0.084 & $0^{* *}$ & 0.290 & 0.510 & 0.988 \\
Are you able to pay to see a dentist? & 0.061 & $0^{* *}$ & 0.247 & 0.436 & 0.969 \\
Are you able to pay for dental medication? & 0.038 & $0^{* *}$ & 0.195 & 0.281 & 0.816 \\
Do you know how to get dentist's appointment? & 0.003 & $0^{* *}$ & 0.054 & -0.491 & 0.138 \\
Are you able to look for a second opinion? & 0.004 & $0^{* *}$ & 0.066 & -0.492 & 0.093 \\
Are you able to carry out dental instructions? & 0.166 & $0^{* *}$ & 0.408 & 0.903 & 1.403 \\
\hline
\end{tabular}

${ }^{*} p \leq 0.05$ significant; ${ }^{* *} p \leq 0.01$ highly significant

Table 4: Logistic regression analysis of responses among schoolchildren toward their OHRQoL using COHIP

\begin{tabular}{|c|c|c|c|c|c|}
\hline \multirow[b]{2}{*}{ Questions } & \multirow{2}{*}{$\begin{array}{l}\text { Regression } \\
\text { coefficient }\end{array}$} & \multirow[b]{2}{*}{$p$-value } & \multirow{2}{*}{$\begin{array}{l}\text { Odds } \\
\text { ratio }\end{array}$} & \multicolumn{2}{|c|}{ 95\% confidence interval } \\
\hline & & & & Lower & Upper \\
\hline Had pain in your teeth/toothache & 0.007 & $0.004^{* *}$ & 0.084 & 0.034 & 0.480 \\
\hline Had discolored teeth or spots on your teeth & 0.004 & 0 ** & 0.060 & 0.500 & 0.118 \\
\hline Had crooked teeth or spaces between your teeth & 0.009 & $0^{* *}$ & 0.096 & 0.596 & 0.001 \\
\hline Had bad breath & 0.005 & $0^{* *}$ & 0.069 & 0.387 & 0.063 \\
\hline $\begin{array}{l}\text { Had difficulty eating foods you like the most because of your teeth/ } \\
\text { mouth or face }\end{array}$ & 0 & $0.004^{* *}$ & 0.012 & 0.189 & 0.245 \\
\hline $\begin{array}{l}\text { Been worried about what other people think about your teeth/mouth } \\
\text { or face }\end{array}$ & 0.004 & $0.004^{* *}$ & 0.064 & 0.088 & 0.424 \\
\hline $\begin{array}{l}\text { Been teased, bullied, or called names by other children because of } \\
\text { your teeth/mouth or face }\end{array}$ & 0.004 & 0.07 & 0.062 & 0.071 & 0.329 \\
\hline Been confident because of your teeth/mouth or face & 0.030 & 0 ** & 0.172 & 0.256 & 0.893 \\
\hline $\begin{array}{l}\text { Felt that you were attractive (good-looking) because of your teeth/ } \\
\text { mouth or face }\end{array}$ & 0.059 & $0^{* *}$ & 0.244 & 0.486 & 1.096 \\
\hline
\end{tabular}

${ }^{*} p \leq 0.05$ significant; ${ }^{* *} p \leq 0.01$ highly significant

Table 5: Mean DMFT scores of children

\begin{tabular}{lllll}
\hline Caries experience & Boys & Girls & $t$-value & $p$-value \\
\hline Mean DMFT & $1.44 \pm 1.57$ & $1.42 \pm 1.74$ & 0.114 & $0.201^{*}$ \\
\hline
\end{tabular}

Unpaired t-test; * $p \leq 0.05$, significant

children. The mean DMFT score between male and female schoolchildren did not differ significantly.

\section{DISCUSSION}

The OHL is defined as the "degree to which individuals have the capacity to obtain, process and understand basic oral health information and services needed to make appropriate health decisions". Internationally, interest in OHL is driven by oral health disparities, particularly for disadvantaged groups, with conditions, such as dental caries contributing substantially to the global burden of disease. Oral diseases and disorders during childhood can have a negative impact on the life of children and their parents. ${ }^{10}$ Perceptions of positive and negative impacts of oral health status on the quality-of-life must necessarily be reported by the people. The importance of oral health beyond dental care is reflected in the World Health
Organization (WHO) Global Oral Health Program. Priority action areas of the $\mathrm{WHO}$ are directed at improving OHL to drive increased knowledge and health-promoting behaviors. ${ }^{8,11,12}$ The HeLD is an instrument that takes a broad approach to OHL. The development and evaluation of the HeLD-14 have been described previously.,

Efforts have been made to develop a measure of OHRQoL that would be appropriate for use with children. The COHIP is a measure of the impact of the oral health, functional well-being, social/emotional wellbeing, school environment, and self-image. ${ }^{7}$ The present study was carried out to assess the association of parental OHL using HeLD with OHRQoL using COHIP-Short Form (SF) among 15-year-old school-going children in Davangere city.

The present study provides information that only $17.1 \%$ of participating students have pain in their teeth, which is in contrast with the study of El Osta et $\mathrm{al}^{13}$ among 12-year-old children in New Caledonia, where $40 \%$ children suffered from pain due to dental problems in the last 3 months. El Osta et al ${ }^{13}$ reported that $26 \%$ of the children claim to have difficulty in chewing food due to dental problems, which is higher when compared with 
the present study where only around 9\% students have difficulty in eating food because of their teeth. This difference might be attributed to sociodemographic behavior and cultural differences in the study population.

A study by Li et al $^{14}$ among 8- to 15-year-old schoolchildren using the Korean version of COHIP concluded that $2.1 \%$ children felt that they are attractive because of their teeth whereas in the present study, the majority of students $(61.9 \%)$ felt that they are attractive. Around 73\% of students in the present study are confident because of their teeth, which is contradictory to the study by $\mathrm{Li}$ et al, ${ }^{14}$ where negligible number of students (2.6\%) felt that they are confident. These variations could be due to differences in the age group, oral hygiene practices, and sociocultural background.

In the present study, $31.2 \%$ parents agreed that they are often able to pay attention to dental health needs and $31.1 \%$ are able to fill in dental forms and more than half of the parents $(51.6 \%)$ are able to pay for a dentist and around $29.6 \%$ are able to carry out instructions given by a dentist. All the above-mentioned results are statistically highly significant. This was the first of its kind using COHIP and HeLD-SF; hence, we could not compare our results with other studies.

\section{Strengths of the Study}

- It can act as a stepping stone for further research to confirm the relationship between OHL of parents and OHRQoL of their children.

- Study participants were recruited from both private and government schools with a varied background. This represents the existing scenario of OHL among their parents.

- The tools used for this study (HeLD-14 and COHIP$\mathrm{SF}$ ) are validated tools that are often used in research across the world.

\section{LIMITATIONS}

- As this study is cross-sectional, it measures cause and effect at the same point in time, introducing the problem of temporal ambiguity and inability in establishing a causal relationship.

- This study involved only 15-year-old students pursuing their education in various streams and their parents. Further studies are recommended in a cross-section of the population represented by all sections of society.

- In the present study, OHL of parents was not found to be associated with OHRQoL of their children. Further trials are suggested to understand the nature and extent of this association. This will aid in developing better oral health care programs for the population.
- Parents were not contacted directly; there is a barrier between trained examiner and parent communication. So, special efforts may be taken to eliminate this barrier.

\section{CONCLUSION}

A number of studies have concluded that higher education levels coincide with positive dental health. ${ }^{15-17}$ However, the present study concluded that the relation of parental literacy and child oral health behavior is not a straightforward cause and effect connection, but rather a more elusive relationship with various external (objective) and internal (subjective) factors playing a role in the process.

\section{RECOMMENDATIONS}

The HeLD and COHIP are simple and may be used in dental practice on a routine basis, to determine their ability in classifying patients based on their OHL levels and designing appropriate parent-centered communication approaches to improve their children's oral health.

More studies are required using HeLD and COHIP in various settings to confirm their ability to detect various degrees of OHL existing in the population and OHRQoL of children. Hence, professional intervention is crucial for improving OHL of parents and OHRQoL of their children.

\section{REFERENCES}

1. Saldunaite K, Bendoraitiene EA, Slabsinskiene E, Vasiliauskiene I, Andruskeviciene V, Z biene J. The role of parental education and socioeconomic status in dental caries prevention among Lithuanian children. Medicina (Kaumas) 2014 Jul;50(3):156-161.

2. Oakada M, Kawamura M, Kaihara Y, Matsuzaki Y, Kuwahara S, Ishidori H, Miura K. Influence of parents' oral health behaviour on oral health status of their school children: an exploratory study employing a causal modelling technique. Int J Paediatr Dent 2002 Mar;12(2):101-108.

3. Rudd RE, Horowitz AM. Health and literacy: supporting the oral health research agenda. J Public Health Dent 2005 Sep;65(3):131-132.

4. Lee JY, Rozier RG, Lee SY, Bender D, Ruiz RE. Development of a word recognition instrument to test health literacy in dentistry: the REALD-30-a brief communication. J Public Health Dent 2007 Spring;67(2):94-98.

5. Do LG, Spencer A. Oral health-related quality of life of children by dental caries and fluorosis experience. J Public Health Dent 2007 Summer;67(3):132-139.

6. Jokovic A, Locker D, Tompson B, Guyatt G. Questionnaire for measuring oral health-related quality of life in eight- to tenyear-old children. Pediatr Dent 2004 Nov-Dec;26(6):512-518.

7. Broder HL, McGrath C, Cisneros GJ. Questionnaire development: face validity and item impact testing of the Child Oral Health Impact Profile. Community Dent Oral Epidemiol 2007 Aug;35(Suppl 1):8-19. 
8. Jones K, Brennan D, Parker E, Jamieson L. Development of a short-form Health Literacy Dental Scale (HeLD-14). Community Dent Oral Epidemiol 2015 Apr;43(2):142-151.

9. Dickson-Swift V, Kenny A, Farmer J, Gussy M, Larkins S. Measuring oral health literacy: a scoping review of existing tools. BMC Oral Health 2014 Dec;14:148.

10. Kinnby CG, Palm L, Widenheim J. Evaluation of information on dental health care at child health centers: differences in educational level, attitudes, and knowledge among parents of preschool children with different caries experience. Acta Odontol Scand 2015;49(5):289-295.

11. Sarnat H, Kagan A, Raviv A. The relation between mother's attitude toward dentistry and the oral status of their children. Pediatr Dent 1984 Sep;6(3):128-131.

12. Williams NJ, Whittle JG, Gatrell AC. The relationship between socio-demographic characteristics and dental health knowledge and attitudes of parents with young children. Br Dent J 2002 Dec;193(11):651-654
13. El Osta N, Pichot H, Soulier-Peigue D, Hennequin M, TubertJeannin S. Validation of the child oral health impact profile (COHIP) French questionnaire among 12 years-old children in New Caledonia. Health Qual Life Outcomes 2015 Oct;13:176.

14. Li C, Xia B, Wang Y, Guan X, Yuan J, Ge L. Translation and psychometric properties of the Chinese (Mandarin) version of the Child Oral Health Impact Profile-Short Form 19 (COHIPSF 19) for school-age children. Health Qual Life Outcomes 2014 Nov;169(12):1-8.

15. Jones M, Lee JY, Rozier RG. Oral health literacy among adult patients seeking dental care. J Am Dent Assoc 2007 Sep;138(9):1199-1208.

16. Miller E, Lee JY, DeWalt DA, Vann WF Jr. Impact of caregiver literacy on children's oral health outcomes. Pediatrics 2010 Jul;126(1):107-114.

17. Garrett GM, Citi AM, Gansky SA. Parental functional health literacy relates to skip pattern questionnaire error and to child oral health. J Calif Dent Assoc 2012 May;40(5):423-430. 